\title{
SOBRE EL ORIGEN, EVOLUCIÓN Y DIVERSIDAD GENÉTICA DE LA PAPA CULTIVADA Y LA SILVESTRE
}

Responsable: Dr. René Chávez Alfaro.

Dedicado al Profesor Jack G. Hawkes, i.m. "The Golden Wonder of the Potato World"

\section{RESUMEN}

La papa cultivada hoy en día en todo el mundo como una de las plantas más alimenticias fue primeramente domesticada en las zonas altoandinas del Perú. Su cultivo se remonta hacia 7000 años atrás basado en evidencias arqueológicas, principalmente de las culturas preincaicas. La papa fue introducida de América del Sur a Europa a fines del siglo XVI, algunos años después del descubrimiento y conquista del Perú. La papa cultivada y sus parientes silvestres poseen una amplia diversidad genética. Más de 200 especies silvestres tuberiferas del genero Solanum han sido identificadas y están agrupadas en una serie de poliploidia desde diploides hasta hexaploides. Estas especies cultivadas de papa están ampliamente distribuidas en los diferentes ecosistemas del continente americano, desde el norte de México hasta el sur de Chile. En general, representan un inmenso recurso genético con genes y alelos valiosos, sistemáticamente utilizados en los actuales programas de mejoramiento genético de la papa para generar clones élites y variedades superiores, mayormente con resistencia a plagas y enfermedades.

\begin{abstract}
The potato that is grown worldwide as one of the major food crops was first domesticated in the highland Peruvian Andes of South America. It was cultivated as far back as 7000 years before present based on archaeological evidence mainly from the coastal pre-Inca cultures. The potato was introduced from South America in to Europe in the late $16^{\text {th }}$ century some years after the discovery and conquest of Peru. The potato crop and its wild relatives have a very wide genetic diversity. More than 200 wild tuber-bearing Solanum species are widely distributed throughout diverse ecosystems of the American continent from northern Mexico to southern Chile and represent an immense genetic resource with valuables genes and alleles currently utilized in the potato breeding programs in order to generate elite clones and superior potato varieties with pest a disease resistance.
\end{abstract}

\section{INTRODUCCIÓN}

El centro genético incásico sudamericano es una de las regiones agricolas más ricas y de mayor diversidad biológica en el mundo, ubicado en las regiones montañosas en los Andes Centrales y constituyendo el asiento más importante como centro de origen genético de un gran número de especies, variedades y ecotipos vegetales útiles al hombre. La papa muestra un gran ejemplo de este hecho; el rol que desempeña en la dieta de la población peruana y en la alimentación mundial es de capital importancia y al presente constituye la planta alimenticia más importante del mundo, después del arroz, el trigo y el maiz.

El proceso de domesticación y cultivo de la papa empezó hace miles de años, en los valles interandinos y las vertientes occidentales de los Andes peruanos, donde el Solanum tuberifero evolucionó en su remarcable diversidad genética. Cuando los europeos llegaron a América, la población andina ya era altamente dependiente de la papa cultivada.

Se calcula que en todo el Tahuantinsuyo, los incas habian logrado domesticar y cultivar cerca de 3,000 variedades agrupadas en ocho especies de papa, de las cuales cerca de 1000 se habrian extinguido.

A la fecha, en los Andes del Perú, Bolivia y Ecuador se cultivan alrededor de 2000 variedades nativas. Hoy en dia el Perủ es el primer productor de papa en América Latina con 3.3 millones de toneladas al año y es el principal sustento alimenticio de más de 450 mil familias que habitan los diferentes ecosistemas andinos.
En muchos paises del hemisferio norte y algunos paises subtropicales como Australia, los agricultores cultivan solamente una especie de papa, el Solanum tuberosum, con unas cuantas variedades. Por ejemplo, cerca de un millón y medio de hectáreas que se cultivan en el norte de EE. UU. y sur de Canadá 1200000 son cultivadas solamente con seis variedades, y cerca de $40 \%$ de esta extensión pertenece a la variedad de procesamiento industrial Russet Burbank, cuyo producto industrialmente procesado en forma de papa prefrita congelada es exportada a más de 100 paises para los restaurantes de comida rápida. Por otra parte, las especies silvestres que hoy en dia habitan en las zonas altoandinas de América del Sur dieron origen a la papa cultivada.

Estas especies han jugado durante más de diez mil años un papel clave en el desarrollo de las variedades nativas y primitivas con resistencia a estreses bióticos y abióticos.

Estas especies silvestres hoy dia representan un gran reservorio y caudal de genes adicionales de recursos genéticos de la papa. En este articulo se enfocan en forma panorámica los caminos y senderos evolutivos, interesantes, misteriosos y controvertidos seguidos por la papa en el tiempo y el espacio desde su origen tan oscuro hasta el presente.

\section{1) Sobre el Origen y Filogenia}

El origen y evolución de la papa cultivada han sido estudiados extensivamente desde la publicación de los resultados de la expedición cientifica de Juzecpzuck y Bukasov a América Central y América del Sur en los años 1925 y 1932 
Estos investigadores por primera vez mostraron al mundo la inmensa variabilidad genética de las papas del Perủ y Bolivia; posteriormente, grandes autores y científicos de la papa, tales como J. G. Hawkes, D. Correll, N. Burton, C. Ochoa y R. Salaman mostraron numerosas evidencias botánicas, ecológicas, genéticas y arqueológicas que llevaron a concluir que en el centro genético sudamericano incásico se habrian domesticado y evolucionado numerosas especies cultivadas tuberiferas hace más de 10000 años, tal es el caso de la papa, la oca, el olluco, la mashua, la maca y otras especies tuberiferas como la yuca y el camote.

El profesor J. G. Hawkes de la Universidad de Birmingham, UK, en su libro Historia de la papa publicado en 1978, sostiene que la región situada entre el Cusco y el Lago Titicaca seria el centro de origen genético inicial de la papa cultivada, porque en esta región altoandina existe un gran número de especies silvestres, variedades nativas, asimismo se habria detectado que la variabilidad genética de los clones primitivos es excepcionalmente alta.

La papa se habría originado bajo condiciones de este ecosistema altoandino hace 10 a 15000 años, a partir de dos especies diploides silvestres de papa: el Solanum canasense y Solanum multidissectum. En el valle altoandino de Vilcanota y sus valles y quebradas afluentes, entre la Raya (4 000 msnm y Urubamba $3000 \mathrm{msnm}$ ), el número de especies (cerca de 20 especies) silvestres de Solanum tuberiferos, morfológica y filogenéticamente afines a la papa cultivada, son marcadamente altos, mas que en ningun otro ecosistema andino sudamericano.

De esta zona la papa habria emigrado a otros valles interandinos y al resto del altiplano, y durante el Imperio Incaico se distribuyó por todo el Tahuantinsuyo, llegando incluso al sur de Chile y al suroeste de Colombia.

La primera especie cultivada que se originó en los Andes fue la especie diploide Solanum stenotonum, $(2 n=2 x=24=$ AA), la cual se habria originado de sus antecesores silvestres Solanum canasense y Solanum multidissectum ampliamente distribuidos en el centro sur del Perú altoandino.

Algunas variedades primitivas lograron ser introducidas en épocas precolombinas a la zona de Chilé, donde a través de miles de generaciones lograron su adaptación a fotoperiodos de dias largos, invierno muy frío y verano templado-cálido. Según Salaman y Hawkes, la papa fue introducida a Europa en 1570, primeramente a España, de alli se dispersó a Inglaterra y el resto de Europa, luego fue introducida a las colonias inglesas de este tiempo, después de ahi paso a Norte América, África, Centro América y paises asiáticos, Japón, la India y China a mediados del siglo XVII.

De esta manera culturas precolombinas de los Andes Centrales habian legado este material genético palpitante llamado papa a la agricultura mundial.

\section{Su Diseminacion Global}

Comparando con otros cultivos, la papa es rica en calorias y proteinas por hectárea.

Es también una buena fuente de importantes vitaminas, especialmente $\mathrm{C}$ y $\mathrm{B}$ y minerales. Corno un cultivo económicamente rentable, es superior a muchas plantas alimenticias en producción de alimentos por hectárea y por dia.

Además, la papa madura en un periodo más corto que muchos cultivos tropicales, adaptándose a cualquier sistema de cultivo.

Normalmente un agricultor de papa utilizando tecnología de punta y variedades mejoradas obtiene más de 40 tn/ha en un periodo vegetativo de 4 a 5 .

En los paises de origen como el Perú, Bolivia, Ecuador y Colombia, la papa es un cultivo principal donde la capa arable está mayormente a más de 3000 m de altitud.

En la actualidad, en el Perú se cultivan 300000 hectáreas y en el mundo cerca de 22 millones de hectáreas y solamente el $11 \%$ en los paises del Tercer Mundo. Cada año se cosecha un promedio de 300 millones de toneladas de papa, en 130 paises.

La República Popular China adiciona otros cinco millones de hectáreas del cultivo de papa.

El bajó rendimiento y la poca extensión del cultivo de la papa en los países del Tercer Mundo, se debería a los estreses abióticos y bióticos que sufre la planta de la papa y a la utilización errónea de variedades inapropiadas, adaptadas a climas templados del hemisferio norte, bajo diferentes condiciones a los trópicos bajos y subtrópicos.

En los paises cálidos, las plagas y enfermedades son problemas muy severos, especialmente en áreas donde los agricultores no pueden solventar la compra de pesticidas con precios exorbitantes.

Es necesario recordar la hambruna catastrófica en los años 1846 - 1848, en Irlanda y parte de Inglaterra, lo cual es un claro ejemplo de la estrecha o poca base genética de la papa que existía en aquella fecha en Europa, ya que se cultivaban millones de hectáreas de unas cuantas variedades, las cuales eran susceptible a la rancha producida por el hongo fitopatógeno Phytophthora infestans. Las condiciones climáticas favorables para el desarrollo del hongo en aquella epoca, tal como densas neblinas y alta humedad atmosférica y calor generaron un ataque masiso y virulento a los cultivos de papa destruyendo las plantas y las cosechas en forma simultanea y seguida. Como consecuencia, un millón de personas murieron de hambre y más de un millón de personas migraron a los Estados Unidos en busca de comida y de un destino mejor.

En aquella época, casi toda la población de Irlanda dependia de la cosecha de papa, y en realidad era un monocultivo masivo y extensivo, basado en 2 ó 3 variedades en toda la isla. A mediados de 1846, apareció el hongo virulento que produce la rancha de la papa y, durante tres años, atacó los cultivos de papa con consecuencias catastróficas conocidas.

A consecuencia de esta catástrofe, Inglaterra y Alemania organizaron expediciones cientificas a Latino américa para encontrar fuentes naturales de resistencia genética a esta enfermedad en el germoplasma silvestre o nativo de la papa, habiendo encontrado en México dos especies promisorias, el 
Solanum demisum con 72 cromosomas y el Solanum verrucosum con 24 cromosomas mostrando una alta resistencia o inmunidad a la rancha de la papa, incluso a la raza más virulenta de este hongo.

Después de 50 años de mejoramiento, en 1920 se genera la primera variedad comercial en Europa, resistente a la enfermedad de la rancha de la papa o Tizón Tardio.

Posteriormente, durante los años 40 , se distribuía a todo el mundo, incluso al Perú, muchas variedades resistentes a esta enfermedad. Hoy en dia cada una de las miles de variedades generadas en los programas de mejoramiento genético poseen algunos genes de resistencia a la Rancha que provienen de estas dos especies silvestres mexicanas.

Dichas especies habían evolucionado durante milenios y adquirido resistencia natural al hongo debido a que en la zona central de México, donde habitan, abundan todas las razas del hongo Phytophthora infestans.

De esta manera también se demostró que los genes de resistencia al hongo de las papas silvestres y los genes virulentos del hongo habian evolucionado paralelamente a través del tiempo y el espacio.

Mientras que un genotipo de planta silvestre de papa resistente al hongo. Los agricultores andinos, por el contrario, han cultivado por milenios un mosaico de variedades nativas, muchas de ellas de excelente textura y gran calidad culinaria.

Un antropólogo ha detectado 46 variedades cultivadas de papa en una sola hectárea en los Andes altos del Perú. Tal vez esta práctica agricola ha sido un medio para asegurar la cosecha, ya que, si una de las tantas variedades cultivadas es diezmada por una sola plaga, enfermedad o por estreses abióticos ambientales, las otras podrian sobrevivir y dar buena cosecha.

\section{ElPotencial Genético y Los Caminos Evolutivos}

En el continente americano existen más de 160 especies tuberiferas silvestres de papa y ocho especies cultivadas.

Estas especies silvestres se expanden solamente en América Latina, desde el norte de México hasta el sur de Chile; desde el desierto costero peruano hasta las selvas húmedas del trópico bajo de Brasil.

Muchas especies habitan en ecosistemas altoandinos por encima de los 3000 metros y algunos florecen y dan tubérculos al pie de los glaciares a $4300 \mathrm{msnm}$, constituyendo este acervo los recursos genéticos más valiosos e importantes para el mejoramiento genético de la papa cultivada en beneficio de la humanidad.

El potencial genético de las especies silvestres de Solanum, especialmente el del Perú, Bolivia y Ecuador, es muy grande. Estas especies contienen un caudal de genes 0 alelos útiles que pueden ser transferidos a las especies cultivadas de papa mediante métodos convencionales de mejoramiento genético a corto y largo plazo así como mediante la biotecnologia molecular e ingenieria genética.
Así, por ejemplo, la especie peruana Solanum acaule y la especie boliviana Solanum magistracrolóbum tienen genes de resistencia a heladas y a muchas razas de virus que atacan las papas cultivadas.

La introducción de material genético valioso de las especies silvestres, con relativa afinidad evolutiva a la papa cultivada, Solanum tuberosum, es considerada actualmente como un enorme potencial en la estrategia del mejoramiento.

La papa cultivada, generalmente, carece de algunos caracteres fenotipicos deseables, que son encontrados en las especies silvestres afines, tales como la resistencia a plagas y enfermedades. Sin embargo, el éxito de la introducción o transferencia de la variabilidad genética de una especie silvestre a la papa cultivada, depende de las afinidades citogenéticas y taxonómicas.

Cuanto más distante es la relación entre las especies, habrá más problemas para obtener hibridos de la primera generación.

Si la especie dominante y la especie receptora son muy afines y no hay restricciones en el apareamiento de cromosomas en la progenie, la transferencia de genes de una especie a otra puede ser llevada a cabo con mucho éxito por métodos convencionales de mejoramiento genético, tales como: hibridaciones introgresivas cruzamientos dialécticos, selección recurrente y pruebas de progenie.

La papa es genética y taxonómicamente una planta cultivada compleja, donde se presenta una serie de ploidias que fluctúan desde especies diploides con 24 cromosomas, hasta especies exaploides con 72 cromosomas.

Esta variabilidad en número de cromosomas, tanto en las especies cultivadas como en las especies silvestres, ha sido un factor limitante en la utilización de material genético promisorio en programas de mejoramiento convencional. Las especies diploides cultivadas, corno la papa amarilla del Mantaro y las silvestres, son autoincompatibles; es decir, que rechazan su propio polen, y sólo aceptan y fecundan el polen de un clon extraño o genéticamente distante.

Esta auto incompatibilidad se llama gametofitica, y es producto de la evolución de la papa hace miles de años para evitar la depresión híbrida por efecto de la endocría. Las especies tetraploides son en cambio autocompatibles y fértiles; a este grupo pertenecen la mayoria de las papas comerciales como Ccompis, Revolución, Peruanita y Tacna.

Las papas triploides y pentaploides son estériles. Estas papas son las que se cultivan a 3500 y 4000 m.s.n.m. en ecosistemas altoandinos y del altiplano de Cuzco y Puno y son resistentes a heladas. Este grupo particular de variedades son las llamadas papas amargas, por su alto contenido del glycoalcaloides como la solanina. Estas papas no se pueden consumir directamente, sino ya deshidratada en forma de chuño negro o moraya.

En realidad la cultura aymara del altiplano peruanoboliviano es una cultura ligada a la Ccañihua y papas amargas, especies altamente resistentes a muy bajas temperaturas $y$ a heladas. Los aymaras fueron los primeros 
en inventar el procesamiento de la papa perecible por secado dando como producto final el chuño y la moraya o yunta, alimento no perecible almacenado para épocas dificiles.

Existen dos teorias acerca de la introducción de las primeras variedades a Europa. Unos autores manifiestan que las primeras variedades primitivas llevadas a Europa correspondian a las variedades de la especie del grupo Andigena, de dias cortos, los cuales no tuberizaron satisfactoriamente en Europa, pero a través de numerosas generaciones de hibridos seedlings o semilla botánica se adaptaron a fotoperiodos de dias largos veranos temperados-cálidos.

Otros autores manifiestan que el material de papa o germoplasma original llevado a Europa corresponderia a la especie del grupo Tuberosum que en aquel tiempo crecia en la zona de Chiloe y estaba adaptado a un clima similar al hemisferio norte con cuatro estaciones bien marcadas.

Recientes estudios citogenéticos, y filogenéticos indican que las papas del grupo Andigena que fueron tempranamente domesticadas por las culturas preincaicas en su camino de expansión habrian sufrido una hibridación introgresiva con una especie diploide silvestre de la zona del Chaco sudamericano, Solanum chacoense, de gran rendimiento.

La papa del grupo Andigena ya mezclada con sangre de $S$. chacoense llegó a Chile y alli evolucionó y se adaptó al clima de esa región, el cual es muy parecido al clima Europeo. Estas variedades adaptadas a días largos denominadas papas Tuberosum habrian sido introducidas en Europa junto con las Andigena, pero fueron los clones del grupo Tuberosum los que demostraron una mayor adaptación al clima y suelo Europeo con buenos rendimientos. Por lo tanto, muchas variedades actualmente mejoradas tendrian genes provenientes de las papas del grupo Andigena y del grupo Tuberosum tal como se muestra en el reciente cuadro evolutivo.

\section{Los Recursos Genéticos y La Ploidía de la Papa}

El género Solanum, al cual pertenece la papa, es uno de los más extensos y complejos géneros dentro dé la familia Solanaceae, conteniendo más de 2000 especies, las cuales se extienden por todo el mundo, excepto en las zonas cerca a los polos.Existe una alta concentración de especies y variedades de Solanum en Sudamérica, Australia y Africa Central. Dentro de este género hay más de 160 especies tuberiferas silvestres filogenéticamente afines a la papa y ocho especies cultivadas.

Tanto las especies silvestres como las cultivadas están ubicadas dentro de la sección Petota de la familia Solanaceae. Afortunadamente, gracias al inmenso esfuerzo y dedicación mistica de los expertos y especialistas en Recursos Genéticos Vegetales, la gran mayoria de las especies silvestres con su diversidad de ecotipos regionales, asi como las variedades nativas y primitivas de papa, han sido colectadas, catalogadas y almacenadas en los bancos de germoplasma, tanto de campo como in vitro, mayormente en el Centro Internacional de la Papa (CIP), Lima, Perú.

Este valioso recurso genético se encuentra siempre disponible para estudiantes, tesistas de agronomia y biologia, para investigadores y para programas de mejoramiento genético de la papa, asi como para biotecnología molecular.

Los Solanum tuberiferos constituyen un grupo taxonómico de plantas extremadamente complejo desde el punto de vista genético y taxonómico.

Debido a la gran variabilidad genética que presentan, ha sido dificil clasificarlos y agruparlos en grupos identificables. Sin embargo, hoy en dia se sabe que las 164 especies de papa silvestre y cultivada están agrupadas en 18 series taxonómicas; las series más importantes o que se conocen se analizan a continuación:

Serie ETUBEROSA.- La serie etuberosa engloba especies diploides muy primitivas, arbustivas y perennes. Ninguna especie tuberiza y es excepcionalmente autocompatible, es decir, se autopolinizan. Son especies valiosas como un gran caudal de genes y alelos de resistencia al virus del enrollamiento de la papa (DLRV) y al mosaico de la papa. además toleran muy bajas temperaturas, habitan en los bosques fríos y húmedos del sur de Chile. El cruzamiento con las especies cultivadas requiere métodos no convencionales, tales como el recojo de ploidia y el cultivo in vitro de embriones. Las especies que más aportaron genes útiles a las cultivadas son: $S$. etuberosuny S. Brevidens.

Serie JUGLANDIFOLIA.- Constituida por especies diploides muy primitivas, arbustiva y perennes, no tuberizan y todas tienen flores amarillas. Filogenéticamente se acercan al lycopersicon de tomate, con el cual también han logrado hibridarse, aunque con extrema dificultad. Contienen genes de resistencia a sequia y salinidad, tal como $S$. lycopersicoides, S. rickii y S. pennellii que habitan en los ecosistemas hiperáridos y desérticos del extremo sur del Perú y norte de Chile entre 1500 y 2500 msnm.

La especie arbustiva S. ochrantum habita en la ceja de selva peruana (2000 $2500 \mathrm{~m}$.) y tienen genes de resistencia al marchitamiento bacteriano (Pseudomonas solanacearum) y posee la baya más grande del mundo delapapa.

Serie CONICIBACATA.- Constituida por especies herbáceas y tuberiferas de hojas compuestas muy disectas y bayas oblongo-cónicas y alargadas con variación cromosómica. Habitan particularmente en las vertientes orientales de los Andes sudaméricanos, ecosistemas de bosques húmedos y nublados del trópico alto del Perú, Colombia, Ecuador y Bolivia.

Con cerca de 20 especies, esta serie representa un recurso genético valioso por su alta frecuencia de genes que tiene para tolerancia a suelos ácidos con toxicidad de hierro y aluminio. Entre las especies peruanas de la ceja de selva alta tenemos a Solanum buesii dedicada al ilustre explorador botánico peruano-alemán Christian Bues, y la especie Solanum neovargasii dedicado al científico y taxonomista de la papa, el profesor Cesar Vargas de la Universidad Nacional del Cuzco. 
Serie DEMISSA.- Especies silvestres de papa mexicanas hexaploides $(6 \mathrm{X})$, tetraploides $(4 \mathrm{X})$ y diploides $(2 X)$ constituyen un gran reservorio de genes y alelos de resistencia a la rancha de la papa phytophthora infestans.

Los genes de $S$. demissum han sido incorporados a clones o cultivares avanzados en los programas internacionales de mejoramiento genético de la papa para resistencia a la rancha.

Hoy en día muchas variedades comerciales de alto rendimiento de papa tienen genes de resistencia horizontal y vertical a la rancha $P$. infestans provenientes de S. demissum de México.

Serie TUBEROSA.- En esta seríe se encuentran cerca de 60 especies silvestres de papa y 8 cultivadas. Todas guardan mucha afinidad filogenética y taxonomica entre si. Sin embargo, existen unas pocas especies genéticamente no muy cercanas a las papas cultivadas.

Cabe destacar esta serie S. sparsipilum (2X), una especie silvestre boliviana que ha contribuido con genes de resistencia a la mancha bacteriana en clones de papas adaptadas al trópico medio bajo.

Asi tenemos: $S$. lephtophyes, $S$. bukasovii, $S$. canascense y S. multidessectum, ancestros silvestres de la papa cultivada y altamente resistentes a muy bajas temperaturas y al nematodo destructor de la papa $G$. Pallida.

Dentro de la serie tuberosa se agrupan las ocho especies cultivadas de la papa de diferente ploidia.

Las Papas Diploides: En el grupo de papas diploides tenemos $(2 n=2 x=24=A A)$ :

stenotonum es una de las especies que muestra una enorme variabilidad genética, cultivada en los Andes altos. La especie S. goniocalyx trae muy pocas variedades, siendo una de ellas la famosa papa amarilla de excelente calidad culinaria del centro del Perú

La especie S. phureja fue domesticada en la zona de los páramos húmedos y templados del norte del Tahuantinsuyo, se caracteriza por la ausencia de una marcada latencia de sus tubérculos y también por precocidad. En el altiplano peruano-boliviano fue domesticada la especie $S$. ajanhuiri similar a las anteriores pero resistente a heladas. Se cree que esta especie altoandina proviene de la hibridación interspectiva y natural de $S$. stenotomum $X$. S. Megistacrolobum.

Dentro del grupo de los diploides se pueden también considerar las papas haploides o dihaploides con 24 cromosomas, mantenidos en bancos genéticos para su utilización en los programas de mejoramiento de clones avanzados.

Los haploides no constituyen variedades o cultivares populares, más bien son "puentes genéticos» 0 progenitores en las hibridaciones avanzadas de papa (2 $x$ por $2 x$ ).
Los haploides se caracterizan por su alto grado de homocigocidad y son obtenidos artificialmente por haploidización sexual y cultivo in vitro de anteras de cultivares tetraploides élites.

Muchos haploides son utilizados en cruzamientos interploidiales $(4 x-2 x)$ debido a su producción de gametos no reducidos (polen $2 n-F D R$ ), lo cual confiere una alta heterosis a la progenie $4 \mathrm{x}$ resultante. Asimismo, se ha experimentado exitosamente que los haploides al grupo Tuberosum $(2 \mathrm{x})$ son puentes excelentes para transferir genes de especies silvestres diploides en cruzamientos $2 x$ por $2 x$. La progenie $2 x$ resultante puede ser elevada a $4 x$, utilizando los gametos $2 n$ de los haploides hibridos.

Las Papas Triploides.- Son papas estériles por su ploidia impar $(2 n=3 x=36)$, lo cual dificulta el apareamiento de cromosomas homólogos en la meiosis.

La especie más conocida en el centro y sur del Perú es Solanum chaucha, la cual es el resultado de una hibridación natural de $S$. tuberosum $(2 n=4 x=48)$ por la especie diploide $S$. stenotomum $(2 n=2 x=24)$. La variedad de mayor popularidad y comercialización es la Huayro.

En el altiplano peruano-boliviano se cultiva intensivamente desde hace miles de años la especie triploide Solanum juzecpzukii.

Las clones o variedades de esta especie son conocidas como papas amargas y se cultivan en promedio a 4000 m.s.n.m. De estas variedades se elabora el chuño y la moraya por congelación y subsecuente deshidratación.

Estas variedades no pueden sancocharse y consumirse directamente debido a su alto contenido de alcaloides solanina, el cual es tóxico para la salud humana.

Pero se consume en forma deshidratada donde se elimina gran parte de la solanina glycoalcaloide. El origen y evolución de S. juzecpzukii es muy interesante y misterioso. Evidencias citogenéticas y agrobotánicas indican que se originó en el altiplano por hibridación natural de la especie cultivada diploide $S$. stenotomum $(2 n=2 x=24)$ y la especie altoandina silvestre $S$. acaule $(2 n=4 x=48)$.

La especie cultivada aportó caracteres agronómicos al hibrido, tales como la alta tuberización y rendimiento mientras que la especie silvestre fue el donante de genes de alta resistencia a heladas y a los virus PVX y PVY de la papa, además del alto contenido del solanina. Esta especie $S$. juzecpzukii constituye un gran aporte a la adaptación y coexistencia del habitante colla y aimara del altiplano, el cual influyó enormemente en su temprana evolución a través de conscientes e inconscientes selecciones orientadas a obtener variedades resistentes a heladas en zonas marginales donde todas las especies y variedades de papa cultivadas sucumben a las condiciones extremas del medio altoandino. 
Las Papas Tetraploides.- Más del $50 \%$ del caudal genético de la papa corresponde a variedades tetraploides $(2 n=4 x=48)$ englobadas en dos subespecies: Solanum tuberosum Ssp Andigena y $S$. tuberosum ssp Tuberosum. Esta especie tiene una gran distribución en los Andes peruanos, desde Ecuador hasta Bolivia. Sus variedades son de gran rendimiento y amplia adaptación.Las papas tetraploides Andigena se originaron por ploidinización natural (FDR) a partir de sus antecesores primitivos diploides.

Las papas Tuberosum se originaron en el sur de Chile y en su evolución migratoria la papa del grupo Andigena se hibridizó con la especie diploide silvestre del Chaco boliviano, S. chacoense. Este hibrido interespecifico migró al sur hasta llegar a Chile, adaptándose a dias largos de verano e inviernos muy fríos de días cortos. Las papas Andigenas se caracterizan generalmente por su gran adaptación, alta variabilidad genética, fertilidad y tolerancia a plagas y enfermedades. Las papas Tuberosum tienen una base genética más angosta y son de altos rendimientos y uniformidad y su relativa susceptibilidad a plagas y enfermedades además de su baja fertilidad.

Las Papas Pentaploides.- Los recursos genéticos de papas pentaploides $(2 n=5 x=60)$ son muy escasos $y$ todos pertenecen a la especie altoandina del altiplano peruano-boliviano Solanum curtilobum. Esta especie al igual que $S$. Juzecpzukii forma parte del acervo genético de las papas amargas y se cultivan para la elaboración de chuño y moraya. La especie Solanum curtilobum, evolucionó en el altiplano peruano boliviano a $4000 \mathrm{~m}$. de altitud a partir de hibridaciones naturales entre la papa tetraploide $S$. tubeosum ssp Andigena y la especie triploide S. Juzecpzukii.

El progenitor del grupo Andigena aportó genes de alto rendimiento mientras que la especie triploide aportó genes de resistencia a heladas y mayor contenido de glycoalcaloides. S. curtilobum se diferencia agronómicamente de $S$. juzecpzukii por su mayor rendimiento, mayor tamaño de tubérculos y follaje y menor grado de resistencia a heladas comparado con $S$. Juzecpzukii.

Las Papas Hexaploides: Al igual que los haploides sólo existen en bancos de germoplasma y no como variedades o cultivares.
Sin embargo, existen especies filogenéticamente afines silvestres que se utilizan sistemáticamente en el mejoramiento como fuente de genes de resistencia a hongos, nemátodos y virus que destruyen los cultivos de papa. Estos son Solanum demisun y $S$. hougasii de la Serie DEMISA y el citotipo hexaploide de $S$. acaule $(2 n=$ $6 x=72$ ). La especie hexaploide del noroeste de Argentina S. oplocence, muy utilizada por sus genes de resistencia al nematodo de la papa Glabodera pallida. La especie $S$. tuberosum ssp Andigena se habria hibridizado naturalmente en sus caminos migratorios y evolutivos por el cono sur de Sudamérica con la especie S. oplocense, adquiriendo de esta forma resistencia genética al nematodo G. Pallida.

Hoy en dia el mejoramiento genético de la papa en el Perú está enmarcado dentro de tres metas o estrategias principales:

a. Mantener una amplia diversidad genética para asegurar un alto rendimiento y estabilidad sostenible.

b. Incrementar la frecuencia de genes que controlan los atributos deseables, tales como la adaptación, rendimiento, resistencia a plagas y enfermedades y tolerancia a estreses abióticos.

c. Estimular la recombinación de atributos deseables en la misma población avanzada y en el mismo genotipo o clon élite.

Finalmente, el inmenso caudal de genes útiles de las papas silvestres y cultivadas viene siendo explotado intensivamente desde el tiempo de los incas hasta nuestros dias, para generar nuevas variedades (nativas) o clones superiores (variedades modernas) adaptadas a las diversas condiciones agroecológicas del Tercer Mundo.

Este caudal de genes constituye hoy para los fitomejoradores modernos una fuente inagotable de recursos genéticos valiosos.

Evaluation of hybrid seedling families in the green house of the university of tacna, 500 masl. (los PichonesTacna). 


\section{EVOLUTIONARY RELATIONSHIPS OF CULTIVATED POTATO SPECIES AND ITS WILD RELATIVES}

J.G. Hawkes; D. Asley; Z. Huaman; P. Schmiediche; M.T. Jackson; L. Lopez ; R. Chavez (1984-1994). Departament of plant Biology. BIRMINGHAM UNIVERSITY, UK.

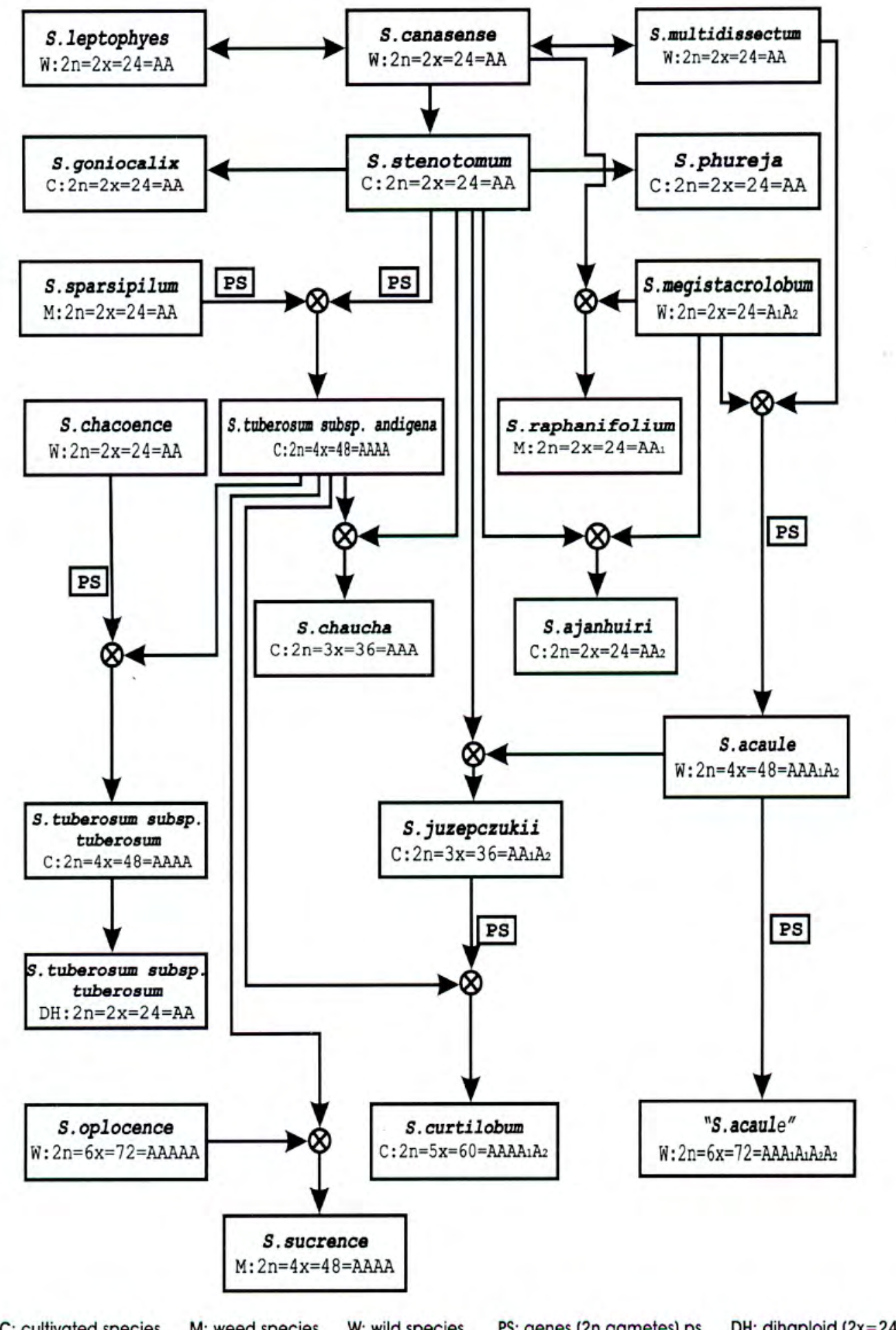

C: cultivated species $\quad$ M: weed species W: wild species PS: genes (2n gametes) ps $\quad$ DH: dihaploid $(2 x=24)$ 


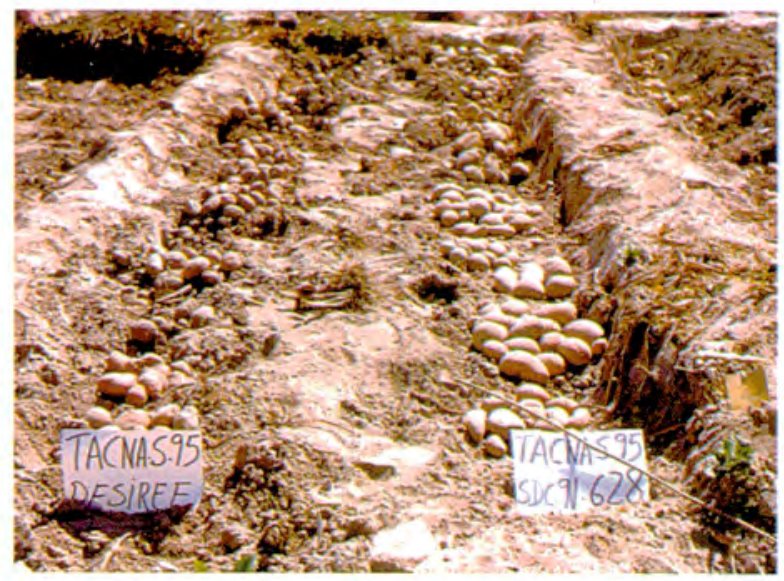

Clon promisorio de papa (SDC91.628) tolerante al estrés de sequia generado en el programa de hibridación y selección del CIP con la Universidad Nacional Jorge Basadre Grohmann de Tacna. Pachía, Tacna, 950 masl.
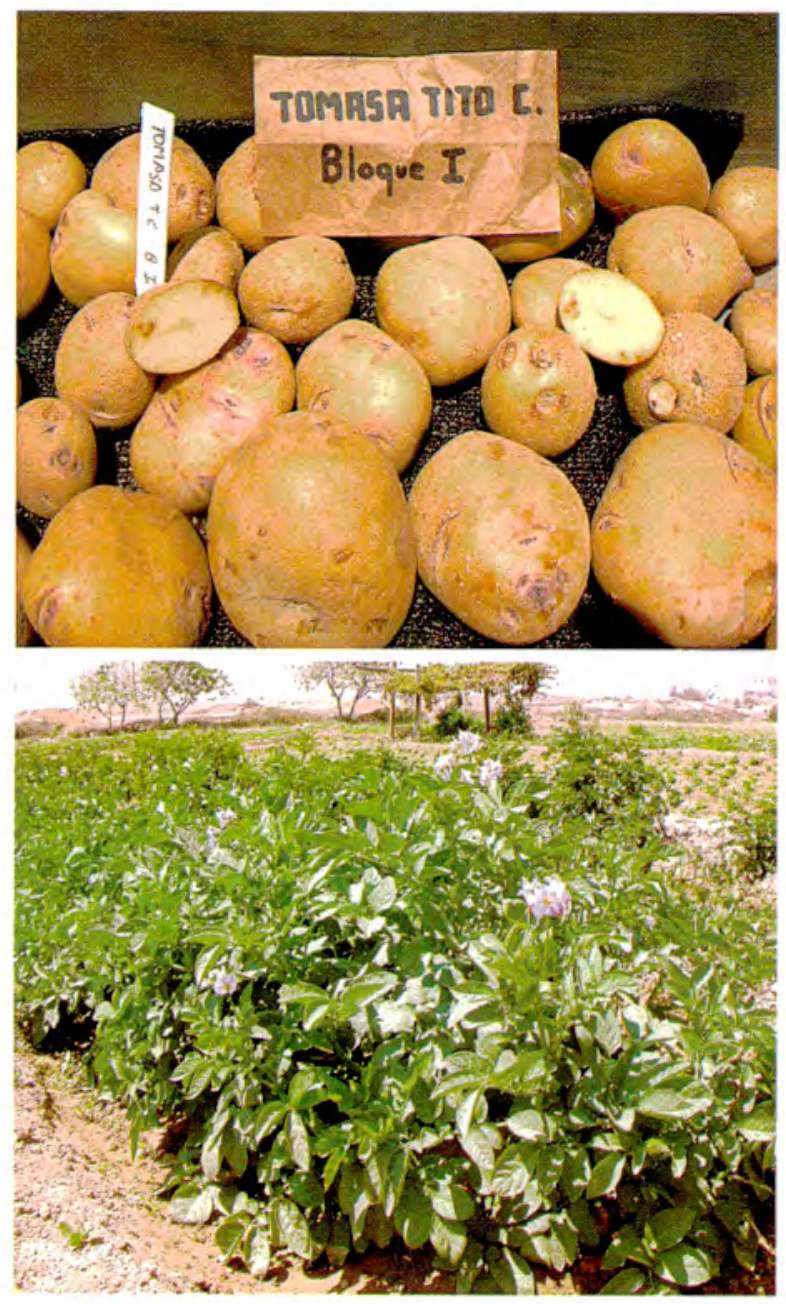

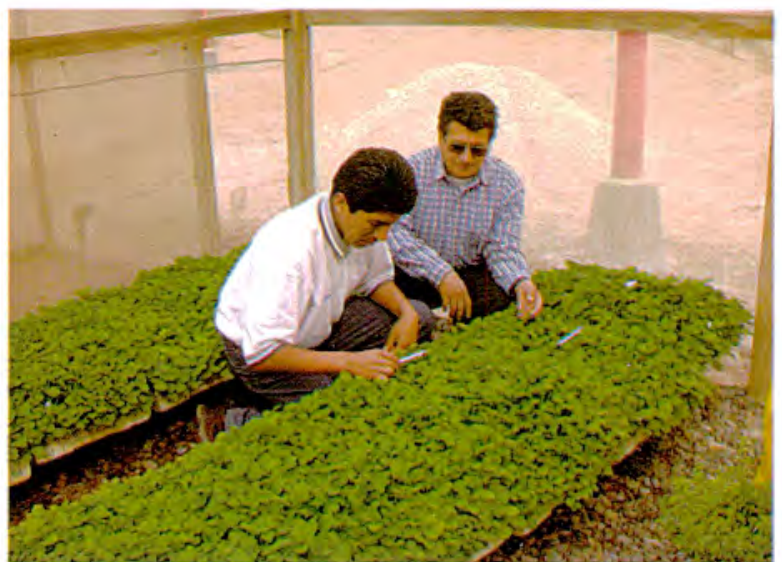

Evaluación de familias híbridas de papa en los invernaderos de la Universidad Nacional Jorge Basadre Grohmann de Tacna. Los Pichones, Tacna, $500 \mathrm{msnm}$.
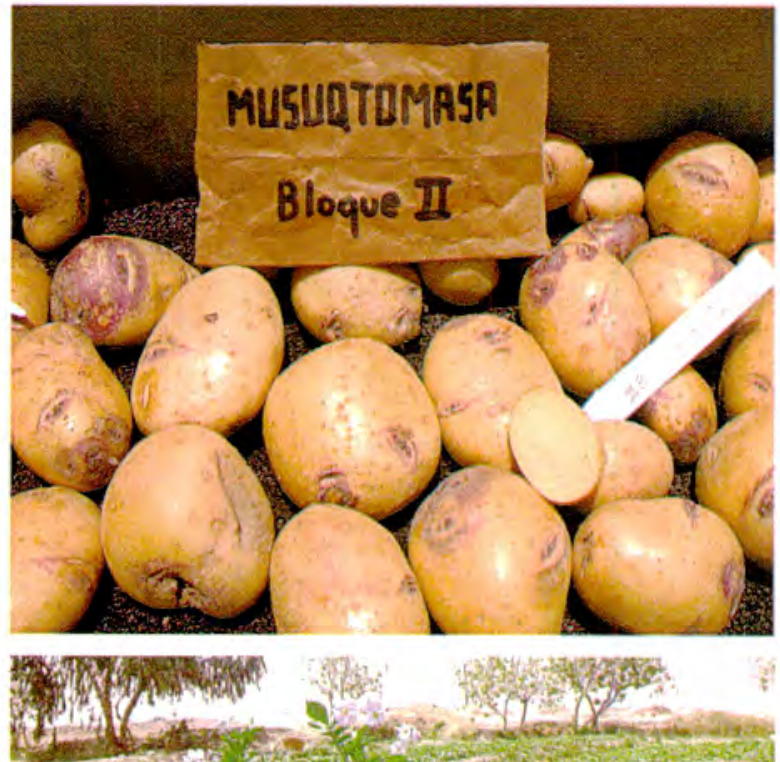

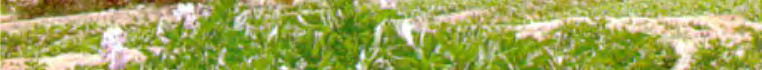

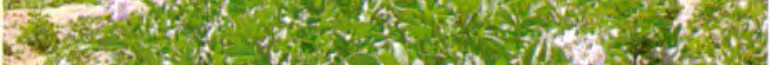

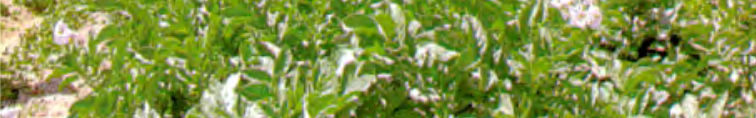
(5)

Desarrollo de una nueva variedad de papa mejorada "Tomasa like" (Musuq Tomasa) con genes de resistencia a los virus PLRX, PVY y PVX mediante mejoramiento convencional como una alternativa a una variedad transgénica resistente a virus. EI Peligro, Tacna, Perú. 850 msnm. 
Frequencia genética de genotipos de papa con tubérculos de cáscara roja en las poblaciones híbridas generadas dentro de los programas de cruzamientos con progenitores de cáscara roja en Tacna.

\begin{tabular}{|c|c|c|c|c|c|c|c|}
\hline $\mathrm{N}^{0}$ & $\begin{array}{l}\text { FELD } \\
\text { CODE }\end{array}$ & TUBER HYBRTD FAMUIY & $\begin{array}{l}\text { RED } \\
\text { SKEN }\end{array}$ & $\begin{array}{l}\text { CRESM } \\
\text { SKaN }\end{array}$ & TOTNL TUBERS & $\begin{array}{l}\text { \$RED } \\
\text { SKN }\end{array}$ & $\begin{array}{l}\text { \% CREAM } \\
\text { SKN }\end{array}$ \\
\hline 1 & TPS01 & CARDINAL X FRIPAPA & 238 & 208 & 446 & 53.36 & 46.64 \\
\hline 2 & TPSO2 & UNICA X FRIPAPA & 326 & 153 & 479 & 68.06 & 31.94 \\
\hline 3 & TPSO3 & P11 XASTERIX & 392 & 276 & 668 & 58.68 & 41.32 \\
\hline 4 & TPSO4 & MEX - 21 X FRIPAPA & 515 & 269 & 784 & 65.69 & 34.31 \\
\hline 5 & TPS05 & MEX -21 X KIGEGA & 248 & 365 & 613 & 40.46 & 59.54 \\
\hline 6 & TPS06 & TACNAX FRIPAPA & 163 & 325 & 488 & 33.40 & 66.60 \\
\hline 7 & TPS07 & ICA NEVADA X FRIPAPA & 434 & 510 & 944 & 45.97 & 54.03 \\
\hline 8 & TPSOB & 27/40 X FRIPAPA & 434 & 230 & 664 & 65.36 & 34.64 \\
\hline 9 & & TESTIGO MUSUQT. & 0 & 305 & 305 & 0.00 & 100.00 \\
\hline 10 & & TESTIGO TOMASA T. C. & 0 & 242 & 242 & 0.00 & 100.00 \\
\hline 11 & TPSO9 & CANCHAN X FRIPAPA & 644 & 428 & 1072 & 60.07 & 39.93 \\
\hline 12 & TPS10 & 27740 X KIGEGA & 253 & 252 & 505 & 50.10 & 49.90 \\
\hline 13 & TPS11 & KIGEGAX FRIPAPA & 130 & 324 & 454 & 28.63 & 71,37 \\
\hline 14 & TPS12 & P12X XRIPAPA & 308 & 360 & 668 & 46.11 & 53.89 \\
\hline 15 & TPS13 & $27 / 40 \times$ MURKA & 552 & 264 & 816 & 67.65 & 32.35 \\
\hline 16 & TPS14 & ICA NEVADA X KIGEGA & 140 & 430 & 570 & 24.56 & 75.44 \\
\hline 17 & TPS15 & M. HUANCA X I-1039 & 140 & 285 & 425 & 32.94 & 67.06 \\
\hline 18 & TPS18 & 393351.15 X FRIPAPA & 178 & 441 & 619 & 28.76 & 71.24 \\
\hline 19 & & TESTIGO TACNA & 0 & 300 & 300 & 0.00 & 100.00 \\
\hline 20 & TPS19 & CANCHAN XI-1039 & 269 & 290 & 559 & 48.12 & 51.88 \\
\hline 21 & TPS22 & GIKUNGO X PUCARA INIA & 367 & 276 & 643 & 57.08 & 42.92 \\
\hline 22 & TPS23 & ASTERIX X FRIPAPA & 230 & 145 & 375 & 61.33 & 38.67 \\
\hline 23 & TPS24 & KINIGI X T10 & 404 & 0 & 404 & 100.00 & 0.00 \\
\hline 24 & TPS25 & ICA PURACE X ASTERIX & 151 & 175 & 326 & 46.32 & 53.68 \\
\hline
\end{tabular}

Desempeño de rendimiento de once clones élites y variedades mejoradas de papa precoces y tolerantes al calor cosechadas a los 100 dias de periodo vegetativo. Valle de Azapa,Arica, 250 m.a.s.I.

\begin{tabular}{|c|c|c|c|c|}
\hline $\begin{array}{r}\text { RANKING } \\
\text { ORDER }\end{array}$ & CLONENARIETY & $\begin{array}{l}\text { TUBER } \\
\text { YIELD } \\
\text { g/ plant }\end{array}$ & Tha & $\begin{array}{l}\text { SIGNIFICATION } \\
\text { AT } 0.05\end{array}$ \\
\hline 1 & R.5186 & 725.5 & 24.18 & a \\
\hline 2 & Tacna & 721.8 & 24.06 & a \\
\hline 3 & M. Tambeña & 719.5 & 23.98 & \\
\hline 4 & Unica & 661.3 & 22.04 & $a$ b \\
\hline 5 & Primavera & 612 & 20.4 & $a b c$ \\
\hline 6 & R-5195 & 554.4 & 18.48 & $a b c d$ \\
\hline 7 & R-5189 & 494.7 & 16.49 & $b c d$ \\
\hline 8 & Reiche & 464.2 & 15.47 & $b c d$ \\
\hline 9 & $R=1568$ & 449.5 & 14.98 & $c d$ \\
\hline 10 & Desiree & 404.7 & 13.49 & $c d$ \\
\hline 11 & Costanera & 367.7 & 12.26 & d \\
\hline
\end{tabular}

Desempeño agronómico general de las variedades Musuq Tomasa y Tomasa Tito y otras variedades usadas como testigo durante la cosecha, cultivada bajo condiciones de estrés de calor. Verano, UNSA, Pedregal, 1400 masl.

\begin{tabular}{|c|c|c|c|c|c|c|c|c|c|}
\hline 8 & $\begin{array}{l}\text { COLORI } \\
\text { WRAETY }\end{array}$ & $\begin{array}{l}\text { SEMESCE } \\
\text { MCE 1-9 }\end{array}$ & $\begin{array}{l}\text { AGRONOMIC } \\
\text { PERFOPBA Is }\end{array}$ & $\begin{array}{l}\text { TUBEER } \\
\text { SLZE 1-8 }\end{array}$ & $\begin{array}{l}\text { SKIN } \\
\text { COLOR }\end{array}$ & $\begin{array}{l}\text { FLESH } \\
\text { COLOR }\end{array}$ & \begin{tabular}{|c|} 
RKN \\
OCCURENGE \\
199
\end{tabular} & \begin{tabular}{|c|} 
HEAT \\
TOLERANCE \\
1.9 \\
\end{tabular} & $\begin{array}{l}\text { TUBER } \\
\text { WeGH } \\
\text { doliant }\end{array}$ \\
\hline $\begin{array}{l}B \\
1\end{array}$ & $\begin{array}{l}\text { UNCACA } \\
\text { CANCHAN } \\
\text { MARIVA } \\
3818651 \\
\text { DESIREE } \\
\text { CAPIRO } \\
\text { ATLANTIC } \\
\text { MURKA } \\
\text { ICANEVADA }\end{array}$ & $\begin{array}{l}9 \\
7 \\
9 \\
1 \\
9 \\
3 \\
9 \\
1 \\
9\end{array}$ & $\begin{array}{l}7 \\
1 \\
3 \\
7 \\
7 \\
1 \\
5 \\
3 \\
1 \\
\end{array}$ & $\begin{array}{l}7 \\
3 \\
3 \\
7 \\
7 \\
1 \\
5 \\
5 \\
1 \\
\end{array}$ & $\begin{array}{l}\text { PINK } \\
\text { RED } \\
\text { PURPLE } \\
\text { RED } \\
\text { PINK } \\
\text { CREAME } \\
\text { CREAME } \\
\text { CREAME } \\
\text { CREAME } \\
\end{array}$ & $\begin{array}{l}\text { PALE YELLOW } \\
\text { PALE YELLOW } \\
\text { DARK YELLOW } \\
\text { CREAME } \\
\text { YELLOW } \\
\text { YELOW } \\
\text { PALE CREAME } \\
\text { WHITE } \\
\text { YELLOW }\end{array}$ & $\begin{array}{l}1 \\
1 \\
1 \\
1 \\
1 \\
1 \\
1 \\
1 \\
1 \\
1 \\
1 \\
3\end{array}$ & $\begin{array}{l}3 \\
3 \\
3 \\
1 \\
7 \\
1 \\
7 \\
3 \\
3 \\
3\end{array}$ & $\begin{array}{l}660 \\
170 \\
440 \\
400 \\
460 \\
260 \\
500 \\
40 \\
170 \\
\end{array}$ \\
\hline $\begin{array}{l}B \\
2\end{array}$ & $\begin{array}{l}\text { CANCHAN } \\
\text { TOMASA } \\
\text { ATLANTIC } \\
\text { JAVILLAS } \\
\text { FRIPAPA } \\
\text { CICA } \\
\text { KINIGI } \\
\text { (CANDARAVE } \\
\text { ICANEVADA } \\
\text { (CANDARAVE)) }\end{array}$ & $\begin{array}{l}9 \\
1 \\
9 \\
9 \\
9 \\
7 \\
3 \\
9 \\
9\end{array}$ & $\begin{array}{l}1 \\
1 \\
5 \\
1 \\
1 \\
1 \\
\\
3 \\
\\
1\end{array}$ & $\begin{array}{l}3 \\
1 \\
5 \\
1 \\
1 \\
3 \\
\\
5 \\
\\
1\end{array}$ & $\begin{array}{l}\text { RED } \\
\text { CREAME } \\
\text { CREAME } \\
\text { RED } \\
\text { RED } \\
\text { PURPLE } \\
\text { PINK } \\
\text { CREAME } \\
\end{array}$ & $\begin{array}{l}\text { PALE YELLOW } \\
\text { CREAME } \\
\text { PALE CREAME } \\
\text { YELLOW } \\
\text { YELLOW } \\
\text { WHITE } \\
\text { CREAME } \\
\text { YELLOW }\end{array}$ & $\begin{array}{l}3 \\
1 \\
1 \\
3 \\
3 \\
1 \\
3 \\
3 \\
1 \\
\end{array}$ & $\begin{array}{l}3 \\
1 \\
7 \\
1 \\
1 \\
1 \\
1 \\
3 \\
3 \\
1\end{array}$ & $\begin{array}{c}160 \\
200 \\
480 \\
200 \\
90 \\
240 \\
\\
640 \\
\\
172 \\
\end{array}$ \\
\hline $\begin{array}{l}B \\
3\end{array}$ & $\begin{array}{l}\text { MUSUQ } \\
\text { UNICA } \\
\text { CHASKA } \\
\text { P.11 } \\
\text { AMARILIS }\end{array}$ & $\begin{array}{l}9 \\
9 \\
9 \\
9 \\
9\end{array}$ & $\begin{array}{l}3 \\
7 \\
1 \\
7 \\
3\end{array}$ & $\begin{array}{l}3 \\
5 \\
1 \\
5 \\
3\end{array}$ & \begin{tabular}{|l|} 
CRAME \\
PINK \\
CREAME \\
CREAME \\
CREAME \\
\end{tabular} & $\begin{array}{l}\text { CREAME } \\
\text { PALE YELLOW } \\
\text { YELOW } \\
\text { WHITE } \\
\text { YELLOW }\end{array}$ & $\begin{array}{l}1 \\
3 \\
3 \\
1 \\
3 \\
\end{array}$ & $\begin{array}{l}3 \\
9 \\
1 \\
7 \\
3 \\
\end{array}$ & $\begin{array}{l}220 \\
680 \\
80 \\
660 \\
200\end{array}$ \\
\hline $\begin{array}{l}B \\
4\end{array}$ & $\begin{array}{l}\text { PERRICHOLI } \\
\text { MARINA } \\
\text { CANCHAN } \\
\text { MONTSAMA-T } \\
\text { MURKA } \\
39335 \\
\end{array}$ & $\begin{array}{l}7 \\
9 \\
9 \\
9 \\
7 \\
9\end{array}$ & $\begin{array}{l}5 \\
3 \\
1 \\
1 \\
3 \\
5\end{array}$ & $\begin{array}{l}5 \\
5 \\
3 \\
3 \\
5 \\
5 \\
\end{array}$ & \begin{tabular}{|l|} 
CREAME \\
PURPLE \\
RED \\
CREAME \\
CREAME \\
PINK \\
\end{tabular} & $\begin{array}{l}\text { WHITE } \\
\text { DARK YELLOW } \\
\text { PALE YELLOW } \\
\text { CREAME } \\
\text { WHITE } \\
\text { YELIOW }\end{array}$ & $\begin{array}{l}1 \\
1 \\
3 \\
3 \\
1 \\
1 \\
\end{array}$ & $\begin{array}{l}5 \\
3 \\
3 \\
3 \\
3 \\
3 \\
3\end{array}$ & $\begin{array}{c}440 \\
460 \\
160 \\
160 \\
50 \\
420 \\
\end{array}$ \\
\hline $\begin{array}{l}B \\
5\end{array}$ & $\begin{array}{l}\text { TOMASA } \\
\text { MUSUQ } \\
\text { JAVLLAS } \\
\text { CAPIRO }\end{array}$ & $\begin{array}{l}7 \\
9 \\
9 \\
9\end{array}$ & $\begin{array}{l}1 \\
3 \\
1 \\
1 \\
\end{array}$ & $\begin{array}{l}1 \\
5 \\
1 \\
1 \\
\end{array}$ & $\begin{array}{l}\text { CREAME } \\
\text { CREAME } \\
\text { RED } \\
\text { CREAME } \\
\end{array}$ & $\begin{array}{l}\text { CREAME } \\
\text { CREAME } \\
\text { YELLOW } \\
\text { YELLOW }\end{array}$ & $\begin{array}{l}1 \\
1 \\
3 \\
1 \\
\end{array}$ & $\begin{array}{l}1 \\
3 \\
1 \\
1 \\
\end{array}$ & $\begin{array}{l}180 \\
200 \\
220 \\
240\end{array}$ \\
\hline $\begin{array}{l}B \\
6\end{array}$ & $\begin{array}{l}\text { MARIVA } \\
\text { PERRICHOLI } \\
\text { CAPIRO }\end{array}$ & $\begin{array}{l}9 \\
9 \\
9\end{array}$ & $\begin{array}{l}3 \\
5 \\
1\end{array}$ & $\begin{array}{l}3 \\
5 \\
1\end{array}$ & $\begin{array}{l}\text { PURPLE } \\
\text { CREAME } \\
\text { CREAME }\end{array}$ & $\begin{array}{l}\text { DARK YELLOW } \\
\text { WHITE } \\
\text { YELLOW }\end{array}$ & $\begin{array}{l}1 \\
1 \\
1\end{array}$ & $\begin{array}{l}3 \\
5 \\
1\end{array}$ & $\begin{array}{l}460 \\
450 \\
250\end{array}$ \\
\hline
\end{tabular}




\section{BIBLIOGRAFÍA}

Burton N. G. (1966) The potato. Ed. Wagemingen. Veenman. Holanda.

Centro Internacional de la Papa (CIP) - Informe Anuales sobre Investigaciones en la Papa. Lima. 1990-2005.

Correll, D. (1962). The potato and its wild relatives. Section tuberarium of the genus Solanum. Texas University Press. USA.

Chávez, R., Mendoza H., Espinoza J., Flores J., Chávez J. Siles P., Huacollo M., ( 1994) "Ampliando la base genética para resistencia a salinidad y sequia en el germoplasma mejorado de papa y camote". Rev. Nueva Imagen, Vol. IV, pp. 13-27, Tacna-Perú.

Chávez R. (2002). Mejoramiento genético de plantas tuberiferas pará zonas Árido-Salinas. Edit. Art Graphics, Tacna-Perú.

Hawkes J. G. (1978). The history of the potato. Edit. P.M. Harris, Chapman Hall. London, UK.
Hawkes J. G. And J. P. Hjerting (1969). The potatoes of Argentina, Brazil, Paraguay and Uruguay. Oxford at the Clarendun Press, UK.

Huamán Z. (1980). Utilization of CIP's primitive potato germplasm to develop improved Back-up population in utilization of the genetics resourses of the potato III-PC-1980, CIP, Press, Lima.

Huamán Z., Golmirzaie A., Amorós W. (1997). The Potato, in Bioviversity Trust, Cambridge University Press, UK.

Mendoza A. (1983) Breeding of potato population at the International Potato Center. CIP, circular II: 1-5.

Ochoa, C. (1999). Las papas de Sud América, Perú. Allen Press, Kansas, USA.

Ochoa, C. (2001). Las papas de Sud América, Bolivia. Cambridge University Press, UK.

Ortiz, R.; Iwanaga, M. (1986). Manipulación de niveles de ploidia en papa. Evaluación agronómica de progenies tetraploides derivadas de cruzamientos $4 x \quad 2 x$. Primer Congreso Peruano de Genética. 1986. 